\title{
A new episode of low back pain: Who relies on bed rest?
}

Citation for published version (APA):

Verbunt, J. A. M. C. F., Sieben, J. M., Vlaeyen, J. W. S., Portegijs, P. J. M., \& Knottnerus, J. A. (2008). A new episode of low back pain: Who relies on bed rest? European Journal of Pain, 12(4), 508-516. https://doi.org/10.1016/j.ejpain.2007.08.001

Document status and date:

Published: 01/01/2008

DOI:

10.1016/j.ejpain.2007.08.001

Document Version:

Publisher's PDF, also known as Version of record

Document license:

Taverne

Please check the document version of this publication:

- A submitted manuscript is the version of the article upon submission and before peer-review. There can be important differences between the submitted version and the official published version of record.

People interested in the research are advised to contact the author for the final version of the publication, or visit the DOI to the publisher's website.

- The final author version and the galley proof are versions of the publication after peer review.

- The final published version features the final layout of the paper including the volume, issue and page numbers.

Link to publication

\footnotetext{
General rights rights.

- You may freely distribute the URL identifying the publication in the public portal. please follow below link for the End User Agreement:

www.umlib.nl/taverne-license

Take down policy

If you believe that this document breaches copyright please contact us at:

repository@maastrichtuniversity.nl

providing details and we will investigate your claim.
}

Copyright and moral rights for the publications made accessible in the public portal are retained by the authors and/or other copyright owners and it is a condition of accessing publications that users recognise and abide by the legal requirements associated with these

- Users may download and print one copy of any publication from the public portal for the purpose of private study or research.

- You may not further distribute the material or use it for any profit-making activity or commercial gain

If the publication is distributed under the terms of Article $25 \mathrm{fa}$ of the Dutch Copyright Act, indicated by the "Taverne" license above, 


\title{
A new episode of low back pain: Who relies on bed rest?
}

\author{
Jeanine A. Verbunt ${ }^{\mathrm{a}, \mathrm{b}, *}$, Judith Sieben ${ }^{\mathrm{c}}$, Johan W.S. Vlaeyen ${ }^{\mathrm{d}, \mathrm{e}}$, Piet Portegijs ${ }^{\mathrm{b}}$, \\ J. André Knottnerus ${ }^{b}$ \\ ${ }^{a}$ Rehabilitation Foundation Limburg, P.O. Box 88, 6430 AB Hoensbroek, The Netherlands \\ ${ }^{\mathrm{b}}$ Department of General Practice, Maastricht University, P.O. Box 616, 6200 MD Maastricht, The Netherlands \\ ${ }^{\mathrm{c}}$ Department of Anatomy/Embryology, Maastricht University, P.O. Box 616, 6200 MD Maastricht, The Netherlands \\ ${ }^{\mathrm{d}}$ Department of Medical, Clinical, and Experimental Psychology, Maastricht University, P.O. Box 616, 6200 MD Maastricht, The Netherlands \\ ${ }^{\mathrm{e}}$ Faculty of Psychology, Leuven University, Tiensestraat 102, 3000 Leuven, Belgium
}

Received 13 May 2007; received in revised form 15 July 2007; accepted 5 August 2007

Available online 17 September 2007

\begin{abstract}
Bed rest has been shown to be an ineffective treatment for non-specific low back pain (LBP). Despite this, during a new episode of pain some patients still rely on bed rest. Which patients choose bed rest is however unknown. The objectives of the present study were, firstly, to assess characteristics of patients choosing bed rest in (sub)acute pain and secondly to study whether prolonged bed rest in the (sub)acute phase of pain will result in long term disability. A prospective longitudinal cohort study included 282 patients with non-specific LBP for less than 7 weeks. Main outcome measures were duration of bed rest (in three categories) and disability. Results showed that $33 \%$ of patients with (sub)acute LBP had bed rest, but only $8 \%$ stayed in bed for more than four days. An ordinal regression analysis revealed that behavioural factors (catastrophizing $(\mathrm{OR}=1.05$ per bed rest category $p<0.01)$ ) and fear of injury $(\mathrm{OR}=1.05$ per category $p<0.01)$ rather than specific pain related factors (pain history $(\mathrm{OR}=0.61$ per category $p=0.16)$ and pain intensity $(\mathrm{OR}=1.00$ per category $p=0.63)$ ) were associated with bed rest. Patients with prolonged bed rest in an early phase of pain were still more disabled after one year $(p<0.01)$. Based on these results we conclude that prolonged bed rest in the early phase of pain is associated with a higher long term disability level. In preventing low back disability, GP screening for catastrophizing and fear of injury in LBP patients who had prolonged bed rest merits consideration.

(C) 2007 European Federation of Chapters of the International Association for the Study of Pain. Published by Elsevier Ltd. All rights reserved.
\end{abstract}

Keywords: Bed rest; Acute low back pain; Predicting factors; Physical activity

\section{Introduction}

For over a century, bed rest has been considered to be the best solution for many musculoskeletal disorders. However, over time this routine has been challenged because of a lack of any evidence supporting its effectiveness (Allen et al., 1999). In acute non-specific low

\footnotetext{
${ }^{*}$ Corresponding author. Tel.: $+31(45) 5282226$; fax: $+31(45) 5282000$.

E-mail address: j.verbunt@srl.nl (J.A. Verbunt).
}

back pain (LBP), bed rest appeared to be less effective than staying active (Hagen et al., 2005). Nowadays, advice to promote physical activity and discourage bed rest in acute non-specific LBP are implemented in many primary care guidelines (Arnau et al., 2006). However, despite their practitioner's advice to stay active, some patients may still choose bed rest during an early phase of LBP. Thus far, the individual characteristics explaining the use of bed rest are unknown. More knowledge about these factors might offer the possibility to target individuals at risk in an early phase of pain. 
The current study will address two possible reasons why persons with acute LBP may choose bed rest (1) A first and straightforward explanation is that patients relying on bed rest perceive a higher level of pain severity. The findings of Rozenberg et al. suggest that patients taking bed rest also used more pain medication and were more often chronic LBP patients, seem to support this explanation (Rozenberg et al., 2004). However, in Rozenbergs study bed rest was often prescribed by the patient's general practitioner (GP) and therefore may not reflect the patient's own choice. Thus it still remains to be determined whether patients who spontaneously choose bed rest have a higher level of pain intensity and/or more often report radiating pain: a symptom, which may alert a physician to a possible hernia nucleus pulposi (Arnau et al., 2006). (2) Alternatively, choosing bed rest perhaps can be approached from a cognitivebehavioural perspective. The fear-avoidance model postulates negative thoughts about pain and its consequences, i.e. pain catastrophizing, as a potential cause for pain related fear, resulting in avoidance behaviour (Vlaeyen et al., 2000). As a result daily activities expecting to cause pain are not performed anymore. Bed rest could be an expression of extreme avoidance of physical activity. Thus avoidance might be associated with fear of movement of a conviction, despite reassurances from their GP, that something is seriously wrong with their back that would be worsened by active movement.

In this study we examine the role of bed rest as a potential risk factor for chronicity; the following research questions will be addressed:

- What are patient characteristics associated with prolonged bed rest during the (sub)acute stage of non-specific low back pain?

- Is bed rest in the (sub)acute phase of pain related to long term pain disability?

\section{Methods}

\subsection{Participants}

Patients with a new episode of LBP were included in this study, which was a part of a larger research-project studying prediction of LBP disability (Sieben et al., 2005a; Bousema et al., 2007). Inclusion criteria: (1) time since pain onset no longer than 7 weeks; (2) pain localised between scapulae and gluteal folds (Merskey and Bogduk, 1994); (3) during the last three months before pain onset, no activity limitations due to back pain; (4) age 18-60 years (5) sufficient knowledge of Dutch language. Exclusion criteria: (1) specific cause for LBP; (2) major psychiatric illness. Patients were enrolled in two different ways: (1) They were invited by one of the 36 participating GPs during a LBP consultation. (2) They responded to an advertisement in a local newspaper. On both occasions a physician performed an interview and physical examination (according the Dutch guideline for primary care LB screening (Arnau et al., 2006)) and referred patients who fulfilled in- and exclusion criteria. Highly fearful patients (TSK $>42$ ) were excluded from participation in the current study, since they participated in the intervention group of an RCT in the current project and thus their natural history could not be observed (Sieben et al., 2005b). All patients gave their written informed consent. The protocol was approved by the Medical Ethics Committee Maastricht, the Netherlands.

\subsection{Baseline measurements}

Within a few days after inclusion participants completed a questionnaire, containing the following items:

Demographic variables. Age, gender, work status and educational level.

Pain episode related variables. Current pain intensity was rated on a VAS with extremes of 0 (no pain) and 100 (unbearable pain) (Bolton, 1999). Information regarding current and former pain episodes was collected by dichotomous items derived from the McGill Pain questionnaire: episodes of pain in history (yes/no), radiation of back pain (yes/no), the onset of pain (sudden/gradual) (Verkes et al., 1989).

Bed rest. To assess duration of bed rest due to LBP, participants were asked to report how long they had stayed in bed during most of the day in the last four weeks as a consequence of their LBP. This question was derived from Patrick et al (Patrick et al., 1995). Answer categories were: no bed rest, 1-4 days (=short bed rest), 5-8 days, 9-14 days and over 14 days. For the present study this question has been translated into Dutch. In addition, the last three answer categories were recoded to one category with bed rest for more than 4 days (=prolonged bed rest).

Fear of movement/(re) injury. The Tampa scale for Kinesiophobia (TSK) is a 17-item questionnaire aimed at the assessment of fear of movement/(re)injury. The Dutch version of the TSK has been reported to have good psychometric properties for patients with low back pain with an internal consistency of Cronbach's $\alpha$ of 0.81 and a criterion validity of $r=-0.54$ with physical task outcome as criterion variable (Roelofs et al., 2007). The predictive validity appeared to be good (Roelofs et al., 2004).

Pain catastrophizing. Pain catastrophizing was scored based on The Pain Catastrophizing Scale (PCS). The PCS consists of three subscales focused on rumination, magnification and helplessness. The PCS has adequate psychometric properties, including internal consistency (Cronbach's $\alpha=0.87)$, test-retest reliability ( $r=0.75$ at 6 weeks) (Sullivan et al., 2001; Damme van et al., 2002). 
Depression. The Dutch version of the Beck depression inventory (BDI) measures depression. It is a 21 -item self-report questionnaire designed to measure the severity of depression and was proposed by the Dutch Committee for the Standardization of Depression Questionnaires (Beck et al., 1979). As advised by Morley et al. for patients with pain, only the BDI-subscale negative view of self was used (Morley et al., 2002).

\section{Physical activity related measures}

Decline in the level of physical activity. In order to reconfirm the accuracy of the classification of bed rest, a second measure for physical activity was introduced: a patient's physical activity decline (PAD) after the onset of pain. The PAD-score expresses a decline in the level of physical activity after the onset of pain as perceived by the patient and is assessed based on self-report. For 20 daily activities, patients were asked if they would have performed this specific activity more often if they had not had back pain. The procedure is described in detail in Verbunt et al. (2005). The internal consistency (Cronbach's $\alpha=0.92$ ) and reliability $(\mathrm{ICC}=0.93$ ) of PAD were shown to be good. The construct-validity of the PAD-questionnaire appeared to be adequate in patients with low back pain $(r=0.55 ; p<0.01)$ (Verbunt, accepted for publication).

The habitual physical activity level. To compare the daily activity level of patients before their back pain started, the habitual activity level was scored based on the Baecke physical activity questionnaire (BPAQ). To be able to score activities in the past, the BPAQ was transformed in the past tense. Patients had to recall their physical activity level during the last year before the back pain started. The BPAQ consists of three indices of habitual physical activity: the occupational activity index; sport activity index and the leisure time activity index. The test retest reliability of the subscales of the BPAQ appeared to be 0.80 for the work-, 0.90 for the sport- and 0.74 for the leisure time index in healthy individuals (Baecke et al., 1982). Validity of the BPAQ in healthy individuals was assessed based a comparison with the criterion variable labelled water technique resulting in a $r$ of $0.69(p<0.001)$ (Philippaerts et al., 1999). In patients with chronic low back pain the testretest reliability of the three subscales of the Baecke varied between 0.77 and 0.90 (Jacob et al., 2001).

\subsection{Follow up measurement}

Pain related disability. Pain related disability was assessed four times over one year to score the impact of pain. Pain related disability was scored using the Quebec back pain disability scale (QBPDS). The QBPDS contains 20 items. Each item is scored from 0 (No difficulty performing this activity) to 5 (Impossible to perform this activity) and the final QBPDS score is expressed with a higher number indicating greater disability. The testretest reliability of the QBPDS appeared to be 0.92 in its original version (Kopec et al., 1995) and 0.90 in the Dutch version (Schoppink et al., 1996). The construct validity of the QBPDS Dutch version seemed 0.80 as tested with its criterion variable Roland disability questionnaire (Schoppink et al., 1996). The disability level was assessed using the QBPDS at time of recruitment and also at 3,6 and 12 months.

\subsection{General practitioners' questionnaire}

To identify possible differences in advice given to the patients, their GP's were asked to complete a questionnaire per patient regarding their advice. All 36 general practitioners who referred patients to this study were asked in addition to fill in a questionnaire concerning the consultation. Twenty-seven GP's completed these questionnaires for 174 patients. Two questions were related to physical activity: (1) Did you advise this patient to stay active? (2) Did you advise this patient to be careful?

\subsection{Analysis}

To answer the first research question, patient characteristics for the three bed rest groups were compared. Differences between groups were tested with: (1) a $\chi^{2}$ analysis for dichotomous variables; (2) a one-way analysis of variance (ANOVA) including a post hoc range test according Tukey for normal distributed continuous variables; (3) a Kruskal-Wallis one-way analysis of variance for non-normal distributed continuous variables. To check the contributing strength of all variables in explaining bed rest, an ordinal regression model (SPSS procedure Polytomous LogitUniversal Models) was used with duration of bed rest as the dependent variable and gender, age, pain intensity, pain history, catastrophizing, negative view of self and the habitual activity level, as independent variables. Ordinal regression OR was used to compare the odds of outcome being above vs. below each of the possible cut- off points (no bed rest vs. bed rest for 1-4 days or $>4$ days, no bed rest or bed rest for 1-4 days vs. bed rest for $>4$ days) when the independent variable increases with 1 unit. Pain intensity, catastrophizing and depression were introduced as independent variables based on their hypothesized association with bed rest as explained in the introduction session. Gender and age were introduced in the model as important demographic variables. In addition, pain history was also introduced based on its significant score in the $\chi^{2}$ analysis. Fear of injury was not introduced in the model because of its conceptual overlap with catastrophizing. In addition, an analysis was performed in which catastrophizing was replaced by fear of injury. 
To address the second research question a linear regression analyses was performed with disability as the dependent variable. Independent variables were bed rest, age, gender, history of pain, pain intensity and the level of disability in the (sub)acute phase. Independent variables were selected based on their hypothesized role as a predictor for long term disability. Age and gender were chosen as important demographic variables. History of pain and pain intensity are added based on their predicting value for disability as it appeared out of earlier studies (Klenerman et al., 1995; Sieben et al., 2005a,b). The initial level of disability was included as a covariate. Finally, bed rest was introduced as the main variable of interest in the model. For all linear regression analyses standardized beta coefficients and their significance were tested under the null hypothesis that the coefficient differed from zero. To control for co-linearity, variable inflation factors (VIF) were checked and had to be below 10. Outliers, if any, with a Cook distance above 1 were removed from the model. All analyses were performed using SPSS software (SPSS Inc., Chicago, IL) version 14.

\section{Results}

Four hundred and sixty-four patients with acute LBP were invited by their GP to participate. Eighty-one refused, 106 did not meet the inclusion criteria and 25 with TSK-scores of $\geqslant 42$ were excluded because they participated in the intervention group of a trial study that was conducted within the cohort. Thirty-four persons were enrolled by means of the advertisement. Of 4 patients data regarding bed rest were missing. A total of 282 patients participated in the current study. Two hundred and thirty-four patients $(83 \%)$ participated in the 3 month follow up, $226(80.1 \%)$ at 6 months and $229(81.2 \%)$ at 12 months. Patients with a TSK $\geqslant 42$ that participated in this study $(N=57)$ and patients with a TSK $\geqslant 42$ that were excluded based on their participation in the intervention group of an additional trial study did not have significant differences regarding age, gender, history of pain and pain intensity.

\subsection{Descriptives}

The main baseline characteristics are presented in Table 1. The mean age of the participants was 43.0 years (SD 10.3). Of these 282,218 persons $(76.2 \%)$ had a paid job and 35 of them $(16 \%)$ were on sick leave. Twenty four of all 282 persons received a full or partial disability pension due to any medical problem (8.4\%). At baseline no differences in the BPAQ score were found, indicating that levels of physical activity before this episode started were comparable in all three groups. At recruitment the
Table 1

Descriptives at baseline $(N=282)$

\begin{tabular}{lrr}
\hline Baseline characteristics & \multicolumn{2}{c}{ Number and percentage } \\
\cline { 3 - 3 } & $N$ & $\%$ \\
\hline Gender & 153 & 54.3 \\
Male & 129 & 45.7 \\
Female & & \\
Educational level & 10 & 3.5 \\
Primary school & 106 & 37.6 \\
Lower vocational & 103 & 36.5 \\
Intermediate vocational & 43 & 15.2 \\
Higher vocational & 15 & 5.3 \\
University & 5 & 1.8 \\
Missing & & \\
\hline
\end{tabular}

median LBP duration for the 282 participants was 7 days with interquartiles of 3 and 20 days.

\subsection{Bed rest}

Ninety-two patients $(33 \%)$ reported bed rest due to LBP, of which $69(25 \%)$ took short bed rest. Only 23 persons $(8 \%)$ had prolonged bed rest. One hundred and ninety patients $(67 \%)$ did not take any bed rest.

To answer the first research question, bed rest groups were compared with respect to demographic, pain related and behavioural characteristics (Table 2). No differences in age, gender and educational level were found. $\chi^{2}$-test showed a significant difference in sick leave status between groups: $8.9 \%$ of patients without, $20 \%$ of patients with short and $13 \%$ of patients with prolonged bed rest were on sick leave at baseline. History of pain differed significantly between the groups: $35 \%$ of patients without, $12 \%$ of patients with short and $50 \%$ of patients with prolonged bed rest had experienced an earlier back pain episode. Further $\chi^{2}$-analysis within a $2 \times 2$ contingency table revealed that the history of pain of the group with short bed rest differed significantly from both the group without bed rest $(p<0.02)$ and the group with prolonged bed rest $(p<0.01)$. However, patients without bed rest and patients with prolonged bed rest had no significant different history of pain $(p=0.25)$. Associations between the duration of bed rest and pain onset, radiation of pain or pain intensity were not found. Regarding cognitive and emotional characteristics, duration of bed rest was significantly related to fear of injury, catastrophizing and depression. Multiple comparisons (post hoc) based on Tukey revealed a significant difference in fear of injury, catastrophizing and depression between patients without and patients with prolonged bed rest (both $p<0.01$ ). In Table 3 the results of the ordinal regression analysis are presented. Because of its conceptual overlap with catastrophizing, fear of injury was excluded from the model. Catastrophizing appeared to have the highest association with bed rest with an OR of 1.05 and a Wald 
Table 2

Characteristics of the three bed rest groups at the(sub) acute phase of pain

\begin{tabular}{|c|c|c|c|c|}
\hline & No bed rest $(N=190)$ & Short bed rest $(1-4$ days) $(N=69)$ & Prolonged bed rest ( $>4$ days) $(N=23)$ & $p$-value \\
\hline \multicolumn{5}{|l|}{ Demographic } \\
\hline Age & $43.3(10.3)$ & $42.6(11.0)$ & $41.6(9.3)$ & 0.78 \\
\hline \multicolumn{5}{|l|}{ Gender } \\
\hline Male & 106 & 34 & 13 & 0.35 \\
\hline Female & 84 & 35 & 10 & \\
\hline \multicolumn{5}{|l|}{ Pain related } \\
\hline \multicolumn{5}{|l|}{ Onset of pain } \\
\hline Sudden & 113 & 47 & 14 & 0.19 \\
\hline Gradual & 77 & 22 & 9 & \\
\hline \multicolumn{5}{|l|}{ Radiation of pain } \\
\hline Yes & 122 & 46 & 8 & 0.76 \\
\hline No & 67 & 23 & 15 & \\
\hline \multicolumn{5}{|l|}{ History of pain } \\
\hline Yes & 139 & 60 & 15 & \\
\hline No & 49 & 7 & 8 & $<0.01$ \\
\hline Pain intensity & $42.3(23.2)$ & $45.7(22.6)$ & $39.4(26.4)$ & 0.27 \\
\hline \multicolumn{5}{|l|}{ Behavioural } \\
\hline Fear of injury (TSK) & $34.0(6.6)$ & $35.1(7.7)$ & $38.8(6.9)$ & $<0.01$ \\
\hline Catastrophizing (PCS) & $14.4(8.2)$ & $17.1(11.3)$ & $21.7(11.0)$ & $<0.01$ \\
\hline \multirow[t]{2}{*}{ Depression $(\mathrm{BDI})^{\mathrm{a}}$} & 4 & 6 & 8 & $<0.01$ \\
\hline & $2-8$ & $2-11$ & $4-15.8$ & \\
\hline \multicolumn{5}{|l|}{ Physical activity } \\
\hline Habitual level of activity (BPAQ) & $8.5(1.3)$ & $8.3(1.3)$ & $8.2(1.3)$ & 0.61 \\
\hline \multirow[t]{2}{*}{ Physical activity decline (PAD) ${ }^{\mathrm{a}}$} & 2 & 6 & 11 & $<0.001$ \\
\hline & $0-6.8$ & $1-9.2$ & $4-15.8$ & \\
\hline
\end{tabular}

Mean scores (SD) are presented.

a Median scores (25-75 quartiles) are presented and non-parametric testing is used because of a non-parametric distribution of the variable.

score of $10.30(p<0.01)$. Similar results are found when catastrophizing is replaced by fear of injury (OR 1.05 $(1.005-1.093))$, and Wald score $4.7(p<0.05)$.

\subsection{Physical activity}

In addition to the bed rest classification, a second measure regarding physical activity was used.

As presented in Table 2, the score for PAD differed significantly between groups $(p<0.001)$. Analysis of Tukey revealed that the score for PAD differed significantly between all three groups.

For 174 patients, the GPs advice, as communicated during consultation, was available. The advice "stay active" was given to $92 \%(N=112)$ of the group with- out bed rest, $89 \%(N=33)$ of the group with a short period of bed rest and $100 \%(N=15)$ of the group with prolonged bed rest. Advice "be careful" was given to $21 \%(N=25)$ of the group without bed rest, $27 \%$ $(N=10)$ of the group with a short period of bed rest and $13 \%(N=2)$ of the group with a prolonged period of bed rest. These percentages did not differ significantly between the groups. Differences in activity related behaviour therefore was not a consequence of the advice given by their GP.

\subsection{Follow up}

In Fig. 1 the disability level is shown during the first year after pain onset presented by bed rest group. At one

Table 3

Ordinal regression analysis with bed rest as dependent variable

\begin{tabular}{lcllcc}
\hline Independent variable & Parameter estimate & Odds ratio & $95 \%$ confidence interval & Wald & Significance level \\
\hline Gender & 0.09 & 1.09 & $0.62-1.91$ & 0.09 & 0.77 \\
Age & -0.01 & 0.99 & $0.96-1.02$ & 0.71 & 0.40 \\
Pain intensity & 0.003 & 1.00 & $0.99-1.02$ & 0.24 & 0.63 \\
History of pain & -0.50 & 0.61 & $0.30-1.22$ & 1.97 & 0.16 \\
Catastrophizing & 0.047 & 1.05 & $1.02-1.08$ & 0.30 & 0.001 \\
Negative view of self & -0.05 & 0.95 & $0.79-1.14$ & 0.28 & 0.60 \\
Habitual activity level & -0.08 & 0.92 & $0.74-1.15$ & 0.47 & 0.49 \\
\hline
\end{tabular}

Ordinal regression OR compares the odds of outcome being above vs. below each of the possible cut-off points (no bed rest vs. bed rest for 1-4 days or $>4$ days, no bed rest or bed rest for 1-4 days vs. bed rest for $>4$ days) when the independent variable increases with 1 unit. 


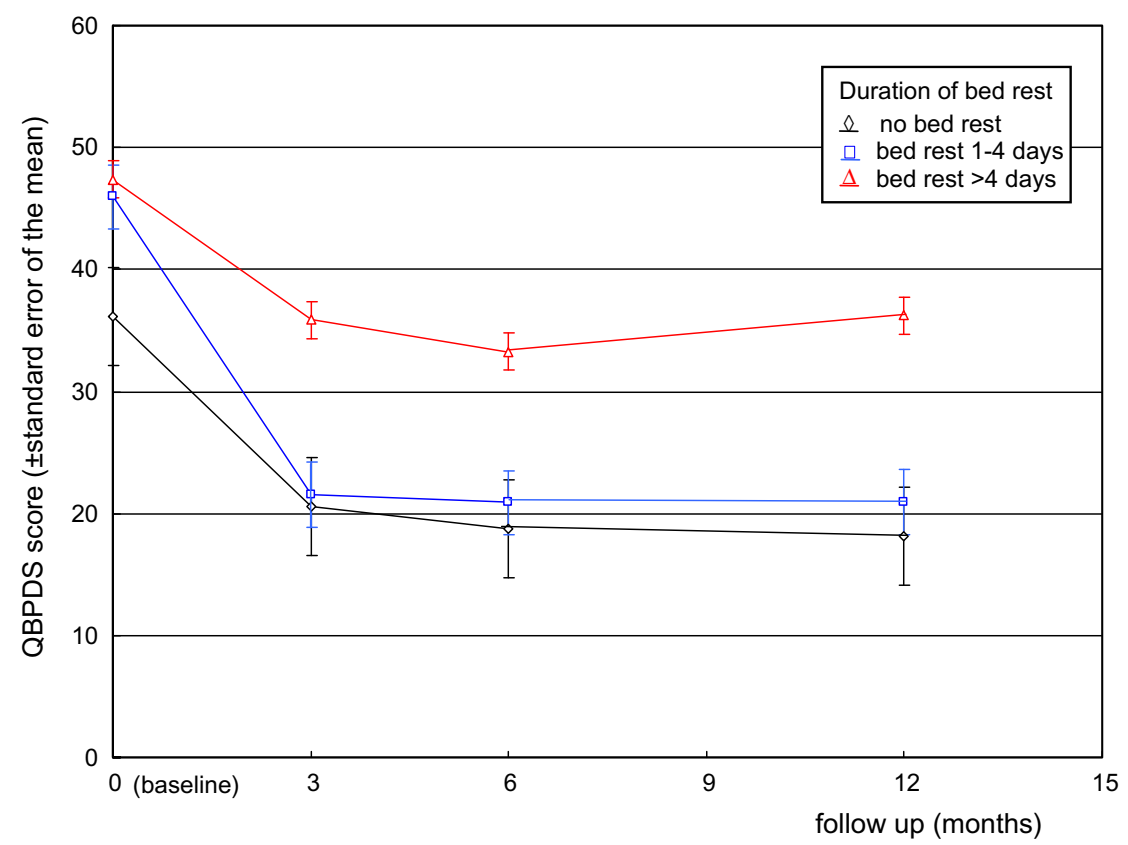

Fig. 1. Perceived disability level during one year follow up after the onset of pain by duration of bed rest. $(N=282)$.

year follow up patients with prolonged bed rest had a QBPDS score of 35.0 ( $\mathrm{SD}=22.2)$ which differed significantly $(<0.01)$ from both patients without $(19.0$ $\mathrm{SD}=17.2)$ and patients with short $(21.5 \mathrm{SD}=17.8)$ bed rest. Bed rest in the early phase of pain appeared to be associated (standardized $\beta$ of $0.16(p=0.02)$ ) with disability after one year after correction for other contributing variables (Table 4). The total explained variance in long term disability was $17 \%$.

\section{Discussion}

\subsection{Principal findings}

Although $33 \%$ of patients with acute LBP chose bed rest, only $8 \%$ stayed in bed for more than four days. It appeared that the choice of bed rest was influenced by cognitive and emotional factors, especially pain catastrophizing and fear of injury. Patients who had bed rest for more than four days during the first weeks after the onset of pain, appeared to be more disabled one year after pain onset.

\subsection{Strengths and weaknesses}

The current study is in our opinion unique for several reasons. First, it addresses both physical and behavioural contributing components in the (sub)acute phase of pain. Although in earlier studies the negative effect of bed rest has been confirmed (Rozenberg et al., 2004; Coste et al., 2004; Pande, 2004), no earlier study was found explaining why persons with acute pain decide to go to bed. Second, the number of 282 participating patients included within seven weeks after pain onset and followed for a year is high compared to other studies.

It is however also important to consider limitations of this study. First, not all data were available for all patients. Self-report measures were assessed in all participants, but data regarding GP advice were only available for a proportion of the patients, which could have resulted in a selection-bias. In addition, at follow up $80.1-83 \%$ of the data was available of all participating patients. However, although this drop out rate of $17-$ $19.9 \%$ resulted in a reduced statistical power, the drop out rate is still low as compared to other cohort studies

Table 4

Linear regression analysis with disability after one year as dependent variable

\begin{tabular}{|c|c|c|c|c|c|}
\hline Dependent variable & Independent variable & $R^{2}$ & Adj. $R^{2}$ & Standardized $\beta$ & $p$-value \\
\hline \multirow[t]{6}{*}{ Disability } & Gender & 0.20 & 0.17 & -0.14 & 0.03 \\
\hline & Age & & & 0.09 & 0.14 \\
\hline & Duration of bed rest & & & 0.16 & 0.02 \\
\hline & Pain intensity at inclusion & & & 0.003 & 0.96 \\
\hline & History of pain & & & 0.12 & 0.06 \\
\hline & Disability at inclusion & & & 0.30 & $<0.01$ \\
\hline
\end{tabular}


in low back pain, for example by Klenerman et al. (1995). Furthermore, highly fearful patients are under presented in our analyses, because we excluded the intervention group of the RCT (Sieben et al., 2005b). However, demographic characteristics of patients with a TSK $\geqslant 42$ that participated in the current study $(N=57)$ and patients with a TSK $\geqslant 42$ that were excluded based on their participation in the intervention group of the trial study $(N=25)$ did not differ. Based on this finding, it can be assumed that the distribution of patients with a high level of fear between the three bed rest groups will not change if more patients with a high level of fear would participate in this study. Thus the exclusion of a part of the patients with a high level of fear will have reduced statistical power, but did not bias the results. A second limitation is the fact that the main outcome variable, bed rest, is based on one single question derived from Patrick et al. (1995). To reconfirm the accuracy of the bed rest classification, another measure regarding physical activity was introduced: PAD. Results on the PAD-score confirmed the classification of activity related behaviour based on the classification of bed rest. The last but important shortcoming is the fact that this study has an observational design and analyses are also performed on cross sectional data. Data concerning patient characteristics and bed rest were measured within the same time-period of (sub)acute phase of pain. If patient characteristics were assessed before the bed rest period started, these could serve as predicting variables for bed rest. However, in the current study design only associations between variables and no causal relationships can be studied.

\subsection{Patient characteristics and bed rest}

The results demonstrate that cognitive and emotional have a stronger influence than pain related factors on the choice of bed rest. This finding favours our second explanation for bed rest: Catastrophizing and fear of injury appeared both related to bed rest in the (sub)acute phase of LBP. This finding is fully in line with the concept of the fear-avoidance model in acute LBP (Vlaeyen et al., 2000). Choosing for bed rest in acute LBP can be interpreted as avoidance behaviour. The first explanation for the choice for bed rest, addressing pain related factors, could not be confirmed in this study. Since the current study focus was directed towards activity related behaviour, a check on passive coping strategies such as using pain medication was not included. However, other pain related variables were neither related to bed rest, which was in accordance with our finding on pain intensity.

In the current study, all patients received identical GP-information regarding the positive effect of staying active. However, especially for patients with catastrophizing thoughts and fear of injury (overpresented in the prolonged bed rest group) encouragement to stay active seemed ineffective to change activity related behaviour. Early recognition of catastrophic misinterpretations, addressing these thoughts and reassuring that being active will not harm, could have an additional value. If this strategy will not be sufficient, graded exposure therapy aimed at reduction of both catastrophizing and fear of injury can be an alternative treatment for those who are extremely and persistently fearful (Sieben et al., 2005b). In line with the results of this study, a patient reporting prolonged bed rest in the early phase of pain, should trigger the physician to identify both catastrophic misinterpretations and fear of injury. If misinterpretations are present it would be of value to reduce the occurrence of these thoughts.

A noteworthy finding was the fact that more patients in the group with prolonged bed rest reported earlier episodes of back pain than patients with short bed rest. Although all participating patients did not have limitations in daily life due to back pain for at least three months before this episode of pain started, it could be that they had pain complaints longer than three months ago. As a result of that, it can be questioned whether they can still be categorized as patients with (sub)acute low back pain or if a classification as chronic low back pain would be more appropriate. It could be that patients with recurrent back pain anticipate and choose bed rest without trying to be active first. In that case, experiences from the past instead of fear can trigger the choice for bed rest. On the other hand, this hypothesis has also to be stated with caution. Although in $2 \times 2$ analysis it appeared that patients with short bed rest had less often back pain complaints in the past than patients with prolonged bed rest, this finding was also present in case the pain history of patients with short bed rest was compared with patients without bed rest. An alternative explanation for the finding that differences on history of pain were present between groups in this analysis could be the fact that results are influenced by a low number of patients within cells. Therefore conclusions on the association between bed rest and history of pain have to be drawn with caution and further research is warranted.

\subsection{Bed rest and long term disability}

In our study, in accordance with earlier studies, bed rest in (sub)acute back pain was found to be associated with long term disability. However, since the explained variance for predicting long term disability as presented in Table 4 was only $17 \%$ conclusions from the current study regarding long term disability prediction have to be drawn with caution. Our findings however seem in agreement with findings of others. In a study of Oleske et al. in which 352 employees reported LBP, bed rest explained a delayed recovery time (Oleske et al., 2004). This finding was confirmed by a systematic review of 
Hagen et al. (Hagen et al., 2005). Malmivaari et al. reported a small significant difference in functional status and length of sick leave compared in favour of staying active as compared to the advice of only 2 days of bed rest Malmivaari et al. (1995). Follow up time of the study of Malmivaari was 12 weeks. In our study patients with short bed rest (1-4 days) were more disabled compared to patients without bed rest at baseline but at 3 months follow up, their disability level was comparable with the level of patients without bed rest. Only prolonged bed rest remained more disabling.

\subsection{Unanswered questions and future research}

Whether addressing high risk LBP patients, based on their choice for prolonged bed rest, will eventually result in a decreased long term disability is still unclear. Confirming this hypothesis needs an intervention study. A second intriguing topic is the fact whether the current findings in patients with low back pain can be generalised to other health conditions. Whether bed rest can be seen as a risk factor for long term disability in other medical conditions is not known.

In summary, catastrophizing and fear of injury rather than pain seem to be associated with a patient's choice for bed rest in the early phase of back pain. Patients who had bed rest for over four days in the acute phase of pain are more disabled after 12 months. Screening for catastrophizing thoughts and fear of injury in patients who report bed rest in the early phase of pain could be of additional value in order to prevent long term disability in back pain. Further research to confirm this hypothesis is however warranted.

\section{Acknowledgements}

The authors want to thank Sita van Riet, Eric Bousema, Henk Seelen, all participating patients and general practitioners for their cooperation. This study was supported by the Council for Medical and Health Research of The Netherlands (ZONMW).

\section{References}

Allen C, Glasziou P, Del Mar C. Bed rest: a potentially harmful treatment needing more careful evaluation. Lancet 1999;354:1229-33.

Arnau JM, Vallano A, Lopez A, Pellise F, Delgado MJ, Prat N. A critical review of guidelines for low back pain treatment. Eur Spine J 2006;15:543-53.

Baecke JA, Burema J, Frijters JE. A short questionnaire for the measurement of habitual physical activity in epidemiological studies. Am J Clin Nutr 1982;36:936-42.

Beck AT, Rush AJ, Shaw BF, Emmery G. Cognitive therapy of depression. New York: John Wiley; 1979.

Bolton JE. Accuracy of recall of usual pain intensity in back pain patients. Pain 1999:533-9.
Bousema EJ, Verbunt JA, Seelen HA, Vlaeyen JW, Andre Knottnerus J. Disuse and physical deconditioning in the first year after the onset of back pain. Pain 2007;130:279-86.

Coste J, Lefrancois G, Guillemin F, Pouchot J. French study group of quality of life in rheumatology. Prognosis and quality of life in patients with acute low back pain: insights from a comprehensive inception cohort study. Arthritis Rheum. 2004;51:168-76.

Damme van S, Crombez G, Bijttebier P, Goubert L, van Houdenhove B. A confirmatory factor analysis of the Pain Catstrophizing Scale: invariant factor structure across clinical and non-clinical populations. Pain 2002;96:319-24.

Hagen KB, Jamtvedt G, Hilde G, Winnem MF. The updated cochrane review of bed rest for low back pain and sciatica. Spine 2005;1:542-6.

Jacob T, Baras M, Zeev A, Epstein L. Low back pain: reliability of a set of pain measurement tools. Arch Phys Med Rehabil 2001;82:735-42.

Klenerman L, Slade PD, Stanley IM, Pennie B, Reilly JP, Atchison LE, et al. The prediction of chronicity in patients with an acute attack of low back pain in a general practice setting. Spine 1995;15:478-84.

Kopec J, Esdaile J, Abrahamowitz M, Abenhaim L, Wood-Dauphines $\mathrm{S}$, Lamping $\mathrm{D}$, et al. The quebec back pain disability scale. Measurement properties. Spine 1995;20:341-52.

Malmivaari A, Hakkinen U, Aro A, et al. The treatment of acute low back pain: bed rest, exercises or ordinary activity? N Engl J Med 1995;332:351-5.

Merskey H, Bogduk N. Classification of chronic pain. Second ed.. IASP Task force on taxonomy. Seattle: IASP Press; 1994.

Morley S, Williams AC, Black S. A confirmatory factor analysis of the beck depression inventory in chronic pain. Pain 2002;99:289-98.

Oleske DM, Neelakantan J, Andersson GB, Hinrichs BG, Lavender SA, Morrissey MJ, et al. Factors affecting recovery from workrelated, low back disorders in autoworkers. Arch Phys Med Rehabil 2004;85:1362-4.

Pande KC. The role of bed rest in acute low back pain. J Indian Med Assoc 2004;102:202-4, 208.

Patrick DL, Deyo RA, Atlas SJ, Singer DE, Chapin A, Keller RB. Assessing Health-related quality of life in patients with sciatica. Spine 1995;20:1899-909.

Philippaerts RM, Westerterp KR, Lefevre J. Doubly labelled water validation of three physical activity questionnaires. Int J Sports Med 1999;20:284-9.

Roelofs J, Goubert L, Peters ML, Vlaeyen JWS, Crombez G. The Tampa scale for kinesiophobia: further examination of psychometric properties in patients with chronic low back pain and fibromyalgia. Eur J Pain 2004;8:495-502.

Roelofs J, Sluiter JK, Frings-Dresen MH, Goossens M, Thibault P, Boersma K, et al. Fear of movement and (re)injury in chronic musculoskeletal pain: Evidence for an invariant two-factor model of the Tampa Scale for Kinesiophobia across pain diagnoses and Dutch, Swedish, and Canadian samples. Pain 2007;131:181-90.

Rozenberg S, Allaert FA, Savarieau B, Perahia M, Valat JP. Le groupe Rachis de la Société Française de rhumatologie. Compliance among general practitioners in France with recommendations not to prescribe bed rest for acute low back pain. Joint Bone Spine 2004;71:56-9.

Schoppink LM, van Tulder MW, Koes BW, Beurskens AJ, de Bie RA. Reliability and validity of the Dutch adaptation of the quebec back pain disability scale. Phys Ther 1996;76:268-75.

Sieben JM, Vlaeyen JWS, Portegijs PJM, Verbunt JA, van RietRutgers S, Kester ADM, et al. Alongitudinal study on the predictive validity of the fear-avoidance model in low back pain. Pain 2005a;117:162-70.

Sieben JM, Portegijs PJM, Vlaeyen JWS, Knipschild P, Kester ADM, Knottnerus A, et al. Exposure in vivo treatment in acute low back pain patients with elevated levels of pain related fear: a randomised 
controlled trial. Chapter in: Sieben JM. Pain related fear in acute low back pain; towards understanding and prevention of chronicity. Thesis Universitaire Pers Maastricht Maastricht 2005b.

Sullivan MJL, Thorn B, Haythornthwaite JA, Keefe F, Martin M, Bradley LA, et al. Theoretical perspectives on the relation between catastrophizing and pain. Clin J Pain 2001;17:52-64.

Verbunt JA, Sieben JM, Seelen HA, Vlaeyen JW, Bousema E, van der Heijden GJ, et al. Decline in physical activity, disability and pain related fear in sub-acute low back pain. Eur J Pain 2005;9: $417-25$.
Verbunt JA. Reliability and validity of the PAD-questionnaire: A measure to assess a pain related Physical Activity Decline accepted. $\mathrm{J}$ Rehabil med, accepted for publication.

Verkes RJ, Vanderiet K, Vertommen H, van der Kloot WA, van der Meij J. De MPQ-DLV: een standaard Nederlndstalige versie van de McGill Pain Questionnaire. Achtergronden enhandleiding. Swets \& Zeitlinger: Lisse; 1989.

Vlaeyen JWS, Linton SJ. Fear-avoidance and its consequences in chronic musculoskeletal pain: a state of the art. Pain 2000;85: 317-32. 